\title{
Problemli Akıllı Telefon Kullanımı ve Ön Psikometrik Özellikleri Ölçeğinin Türkçeye Uyarlanması
}

\author{
Ezgi Pelin YILDIZ \\ Kafkas Üniversitesi Kazım Karabekir Teknik Bilimler Meslek Yüksekokulu \\ Bilgisayar Programcılığı Bölümü \\ yildizezgipelin@gmail.com \\ ORCID ID:https://orcid.org/0000-0002-9987-9857 \\ Metin ÇENGEL \\ Sakarya Uygulamalı Bilimler Üniversitesi, Hendek Meslek Yüksekokulu \\ Bilgisayar Programcılığı Bölümü \\ cengel@ sakarya.edu.tr \\ ORCID ID: https://orcid.org/0000-0001-6049-5015 \\ Ayşe ALKAN \\ Samsun İl Milli Eğitim \\ ayse.alkan55@gmail.com \\ ORCID ID: https://orcid.org/0000-0002-9125-1408
}

Araştırma Makalesi

DOI: $10.31592 /$ aeusbed.621424

Geliş Tarihi: 17.08.2019

Revize Tarihi: 17.05 .2020

Kabul Tarihi: 18.05 .2020

\section{Atıf Bilgisi}

Yıldız, E. P., Çengel, M. ve Alkan, A. (2020). Problemli akıllı telefon kullanımı ve ön psikometrik özellikleri ölçeğinin Türkçeye uyarlanması. Ahi Evran Üniversitesi Sosyal Bilimler Enstitüsü Dergisi, 6(2), 516-530.

\section{ÖZ}

Günümüzde gelișen ve sürekli değișime uğrayan bilgi ve iletișim teknolojileri bazı bağımlılıkların hayatımıza girmesine zemin hazırlamıştır. Bu bağımlılıklardan biri de nomofobidir. Connecticut Üniversitesi'nde bir araştırmac1; David Greenfield bu bağımlılığı İngilizce de "nomobilephone" kelimelerinin birleşmesinden meydana gelen Nomophobia (Nomofobi) kelimesi ile tanımlamıştır. Nomofobi terim olarak, akıllı telefon kullanımı ile ilgili problemli kullanım, davranış ve/veya semptomların bir koleksiyonunu ortaya koymaktır. Ülkemizde akıllı telefonların kullanımı dikkate alındığında bireylerin problemli akıllı telefon kullanımına ilişkin göstermiş oldukları davranışsal reaksiyonların neler olduğunun belirlenmesi önem taşımaktadır. Özellikle bu kaygının, bireylerin günlük işlere odaklanmasını etkiler nitelikte olduğu açıktır. Bu çalışmada, bireylerin problemli akıllı telefon kullanımları ve ön psikometrik özelliklerinin belirlenmesi adına Merlo, Stone ve Bibbey (2013) tarafından geliştirilen ilgili ölçeğin Türkçe'ye uyarlama çalışması yapılmıştır. Ölçeğin geçerlik ve güvenirlik çalışmaları, kamu ve özel eğitim kurumlarında çalışan 290 öğretmenden elde edilen verilerle gerçekleştirilmiştir. Ölçeğin kapsam ve görünüş geçerliği için 1 dil uzmanına, 3 alan uzmanına, 1 psikolojik danışmana, 1 ölçme değerlendirme uzmanına başvurulmuştur. Alınan uzman görüşlerinden sonra gerekli görülen düzenlemeler yapılmış ve pilot uygulama için deneme formu oluşturulmuştur. Pilot uygulamada, asıl uygulamaya eş değer 15 kișilik bir grup ile çalıșılmıștır. Pilot uygulama sonucunda öğrenciler tarafından anlaşılmayan maddeler değiştirilmiş ve tekrar uzman görüşü alındıktan sonra ölçeğin asıl formu oluşturulmuştur. Yap1 geçerliğini test etmek için Açımlayıcı Faktör Analizi'nden (AFA) yararlanılmıştır. Çalışma sonunda toplam varyansın \%54,76'sını açıklayan 20 maddeden oluşan 3 boyutlu bir ölçek elde edilmiştir. Ölçeğin Cronbach Alpha ile hesaplanan iç tutarlık katsayısı .91' dir. Doğrulayıcı faktör analizine ilişkin 3 boyut bağlamında nihai uyum indekslerinin istenilen sınırlarda olduğu tespit edilmiştir.

Anahtar Kelimeler: Problemli akıllı telefon kullanımı, nomofobi, geçerlik, güvenirlik.

\section{Adaptation of Problematic Smartphone Use and Anterior Psychometric Characteristics Scale into Turkish}

\section{ABSTRACT}

Nowadays, the information and communication technologies that are developing and constantly changing have prepared the ground for the entry of some dependencies into our lives. One of these dependencies is nomophobia. A researcher at the University of Connecticut; David Greenfield described this addiction with the word Nomophobia (Nomophobia), which consists of the combination of the words NO MOBILE PHONE in English. Nomophobia as a term refers to a collection of problematic use, behavior and / or symptoms associated with smartphone use. Considering the use of smart phones in our country, it is important to determine the behavioral responses of individuals towards problematic smart phones. In particular, it is clear that this concern affects individuals' focus on daily work. In this study, adaptation of the related scale developed by Merlo, Stone and Bibbey (2013) to Turkish in order to determine problematic smartphone 
usage and preliminary psychometric properties of individuals was conducted. Validity and reliability studies of the scale were carried out with data obtained from 290 teachers working in public and private educational institutions. The validity and reliability studies of the scale were carried out with the participation of 290 teachers working in public and private educational institutions. 1 language specialist, 3 field experts, 1 psychological counselor, 1 measuring and evaluation specialist were used for the scope and appearance validity of the scale. After the expert opinions, necessary arrangements were made and a trial form was created for pilot implementation. In pilot practice, a group of 15 people, equivalent to the actual practice, was studied. As a result of the pilot implementation, the items that were not understood by the students were changed and the original form of the scale was created after receiving the expert opinion again. Exploratory Factor Analysis (AFA) was used to serve construct validity. At the end of the study, a 3 dimensional scale consisting of 20 items explaining $\% 54,76$ of the total variance was obtained. The internal consistency coefficient of the scale calculated by Cronbach Alpha was .91.The final fit indexes were found to be within the desired limits in the context of 3-dimensional confirmatory factor analysis.

Keywords: Problematic smartphone usage, nomophobia, validity, reliability.

\section{Giriş}

Günümüzde bilginin artmasıyla beraber teknoloji de aynı paralellikte gelişmektedir. Gelişen teknoloji insan hayatının her safhasında önemli rol oynamaktadır (Kağızmanlı, Tatar ve Zengin, 2013). Geçmişten günümüze teknoloji insan hayatının merkezinde yer aldığı için, gündelik ihtiyaçların temini noktasında teknolojiden istifade edilmiştir (Sarı ve Kartal, 2018). Günümüzde bilim, sanayi ve teknolojide hızlı değişimler yaşanmakta ve bu değişimler bireylerin yaşam şekillerini değiştirip dijitalleşmeye götürmektedir (Özbay ve Sarıca, 2019). Bu bağlamda bireyler sadece bir tuş sayesinde iş yeri, okul, banka gibi alanlardaki tüm işlerini zamandan ve mekândan bağımsız olarak yönetmeye başlamışlardır. $\mathrm{Bu}$ tür kolaylıkları insan hayatına geçiren en önemli araçlardan biri de akıllı telefonlardır. Teknolojik gelişmeler (özellikle internet tabanlı olanlar) dünya çapında her zamankinden daha fazla insanı kendine çekmiş durumdadır. Bugün milyarlarca insan sosyalleşmek için bu topluluklara katılma eğilimindedir (Yüksel ve Durmaz, 2016). Bu bağlamda ülkemizde akıllı telefon kullanımı düzeyi anlamında Türkiye İstatistik Kurumu (TÜIK) 2019 verileri incelendiğinde; yetişkin insanların \%98'inin cep telefonu, bunların \%77'sinin ise akıllı telefon kullandıkları ortaya konulmuştur. Bu oranlar doğrultusunda akıllı telefonlara karşı olan bu düşkünlük ve akıllı telefonların sunduğu imkânlara erişememe korkusu bireylerde psikolojik rahatsızlıklara yol açmıştır.

Connecticut Üniversitesi araştırmacısı David Greenfield bu psikolojik rahatsızlı̆̆ İngilizce de "no mobile phone" kelimelerinin birleşmesinden meydana gelen Nomophobia (Nomofobi) kelimesi ile tanımlamıştır. Klinik psikolojide yapılan nomofobi tanımı; "bireylerin akıllı telefonlarına erişemediği ve/veya akıllı telefonları üzerinden diğer kişilerle iletişime geçemediği zamanlarda yaşadıkları mantık dışı ve istemsiz kaygı olarak tanımlanmaktadır (Yildirim ve Correia, 2015). Nomofobik davranış ve semptomları gösteren bireyler, akıllı telefonları yanında olmadıklarında, şarjları bittiğinde ve/veya cihazları kapsama alanı dışında olduğunda ansızın kaygı duymaya başlarlar hatta cihazları yanlarında olsa bile obsesif bir şekilde kontrol etme gerekliliği duyarlar (Adnan ve Gezgin, 2016; Algül, 2014; Dixit, Shukla, Bhagwat, Bindal, Goyal, Zaidi ve Shrivastava, 2010; Gezgin ve Çakır, 2016; Pavithra ve Madhukumar, 2015; Sharma, Sharma, Sharma ve Wavare, 2015; Yildirim, Sumuer, Adnan, ve Yildirim, 2015). Bu tür davranışların yanı sıra sağlık boyutunda baş dönmesi, nefes darlı̆̆1, mide krampları, anksiyete gibi semptomların varlığı da nomofobi adına dikkat çekicidir (Thomee, Harenstam ve Hagberg, 2011).

Yapılan araştırmalarda son dönemlerde nomofobinin insan yaşamında etkili olduğu ortaya konulmuştur. İngiltere'de SecurEnvoy adlı araştırma şirketi tarafından 2012 yılında 1000 kişi ile yapılan araştırmada ise katılımcıların \%66'sının nomofobi düzeylerinin yüksek olduğu görülmüştür. Fransa'da üniversite öğrencileri üzerinde yapılan bir araştırmada her 3 öğrenciden birinin nomofobik birey olduğu tespit edilmiştir (Tavolacci, Meyrignac, Richard, Dechelotte ve Ladner, 2015). KaplanAkıllı ve Gezgin (2016), yaptıkları araştırmada üniversite öğrencilerinin nomofobi düzeyleri ile farklı davranış örüntülerinin arasındaki ilişkilerin incelenmesi bağlamında 683 üniversite öğrencisiyle çalışmışlardır. Sonuç olarak; iki alt boyut: bilgiye erişememe ve iletişime geçememe anlamında nomofobinin üniversite öğrencileri arasında yaygınlaştı̆̆ı ortaya konulmuştur. Dağl1, Gezgin ve Hamutoğlu (2017), araştırmalarında okul öncesi öğretmenleriyle çalışmışlar; sonuç olarak öğretmenlerin akıllı telefonları ile sosyal ağlarda günlük geçirdikleri zaman arttıkça nomofobi 
düzeylerinde artış olduğunu tespit etmişlerdir. Anshari, Alas ve Sulaiman (2019), araştırmalarında akıllı telefon bağımlılığı ve nomofobinin gençler üzerindeki etkisini incelemişler, sonuç olarak; güvensiz hissetme, panik-korku-endişe, anti sosyallik, bağımlılık-sosyal medya bağımlılığı, sağlık sorunları nomofobinin önde gelen davranış ve semptomları olarak ortaya konulmuştur.

İlgili konuya yönelik geliştirilen ölçekler incelendiğinde; Yıldırım vd., (2016) çalışmalarında “Türkçe Nomofobi Ölçeğini” ortaya koymuşlardır. 5'li likert tipinde hazırlanan ölçek toplamda 20 maddeden oluşup, 4 boyutludur. Bu boyutlar, "bilgiye erişememe, rahatliktan feragat etme, iletişim kuramama ve çevrimiçi bağlantıyı kaybetme" olarak belirlenmiştir. Ölçeğin geçerlik ve güvenirlik çalışmaları incelendiğinde Cronbach's alpha değeri .95 olarak tespit edilmiştir. Bu değerin 0-1.00 arasında olması yüksek derecede güvenilir olduğunu göstermektedir (Tavşancıl, 2006). Ölçeğin yapısını doğrulamak için Doğrulayıcı Faktör Analizinden yararlanılmış buna göre ön testte uyum indeksleri tatmin edici derecede yüksek bulunmuştur.

Kwon, Kim, Cho ve Yang (2013) ise ergenler için "Akıllı Telefon Bağımlılık Ölçeğini”" geliştirmişler; bu bağlamda 33 madde ve 6 boyuttan oluşan bir yapı üzerinde çalışmışlardır. Ölçeğin geçerlik ve güvenirlik çalışmaları incelendiğinde Cronbach's alpha değeri .96 olarak tespit edilmiştir. $\mathrm{Bu}$ değerin 0-1.00 arasında olması yüksek derecede güvenilir olduğunu göstermektedir (Tavşancıl, 2006). Geliştirilen ölçek yaşları 14-15 arasında değişen toplamdda 540 öğrenciye uygulanmıştır. Sonuç olarak, araştırmaya katılan ergenlerin akıllı telefon bağımlılı̆̆ı açısından yüksek risk grubu altında oldukları saptanmıştır.

Tüm bunlar ışında bu çalışmanın amacı; problemli internet kullanımının ön psikometrik özelliklerinin bireyler üzerindeki etkisinin belirlenmesine yönelik alan yazında var olan geçerlik ve güvenirliği kanıtlanmış bir ölçeğin Türkçe'ye uyarlanmasını gerçekleştirmek ve ileriki çalışmalarda veri toplama aracı olarak kullanılmasını sağlamaktır.

\section{Yöntem}

$\mathrm{Bu}$ araştırma bir ölçek uyarlama çalışmasıdır. Araştırma amacına yönelik detaylı bir alanyazın taraması yapılarak ölçeğin kavramsal çerçevesi ortaya konulmuş, çalışma grubuna ve ölçeğin geliştirilme sürecine yönelik bilgiler ve izlenen adımlar aşağıda verilmiştir.

\section{Araştırma Deseni}

$\mathrm{Bu}$ çalışmada, katılımcılar arasında halihazırda var olan farklılıkların nedenlerine ve sonuçlarına odaklanan nedensel karşılaştırmalı bir araştırma tasarımı kullanılmıştır (Fraenkel vd., 2012). İlgili yöntem belli bir değişken açısından farklılaşan grupları birbiriyle karşılaştırmak amacıyla kullanılmaktadır. Buna göre bu çalışmada, süreç boyunca gönüllü katılımı kabul eden üniversite öğrencilerinin nomofobik davranışları bir ölçek yardımıyla tespit edilmeye çalışılmıştır. Katılımcılar araştırma öncesinde tanınmış ve verdikleri yanıtların gizli kalması hususuna önemle dikkat edilmiştir.

\section{Çalışma Grubu}

Araştırma grubunu oluştururken amaca uygun ve kolay ulaşılabilmesi için uygun örneklemeden yararlanılmıştır. Uygun örnekleme, araştırmacının rahatlıkla ulaşabileceği örneklem elemanlarını almayı içerir (Monette, Sullivan ve Dejong, 2005).

Araştırmanın örneklemini Sakarya ilinde kamu ve özel eğitim kurum ve kuruluşlarında görev yapan 290 öğretmen oluşturmaktadır. Çalışmanın grubuna ait demografik veriler tablosu aşağıdadır: 
Tablo 1

Çalışma Grubuna Ait Demografik Veriler

\begin{tabular}{|c|c|c|c|}
\hline & & $\mathrm{f}$ & $\%$ \\
\hline \multirow[t]{2}{*}{ Cinsiyet } & Kadın & 159 & 54,2 \\
\hline & Erkek & 131 & 45,8 \\
\hline \multirow{5}{*}{ Yaş } & $21-25$ & 20 & 6,9 \\
\hline & $26-30$ & 53 & 18,3 \\
\hline & $31-35$ & 56 & 19,3 \\
\hline & $36-40$ & 39 & 13,4 \\
\hline & $40+$ & 122 & 42,1 \\
\hline \multirow{3}{*}{ Eğitim Durumu } & Lisans & 215 & 74,1 \\
\hline & Yüksek Lisans & 71 & 24,5 \\
\hline & Doktora & 14 & 1,4 \\
\hline \multirow{9}{*}{ Branş } & Bilişim & 12 & 4,2 \\
\hline & Okul Öncesi & 8 & 2,8 \\
\hline & Sinif & 67 & 23,1 \\
\hline & Matematik & 16 & 5,5 \\
\hline & Fen Bilgisi & 18 & 6,2 \\
\hline & Sosyal Bilgiler & 8 & 2,8 \\
\hline & Türkçe & 20 & 6,9 \\
\hline & Beden Eğitimi & 6 & 2,1 \\
\hline & Diğer & 135 & 46,6 \\
\hline \multirow[t]{2}{*}{ Kurum } & Kamu & 207 & 71,4 \\
\hline & Özel & 83 & 28,6 \\
\hline \multirow{5}{*}{ Kademe } & Okul Öncesi & 10 & 3,4 \\
\hline & İlkokul & 80 & 27,6 \\
\hline & Ortaokul & 96 & 33,1 \\
\hline & Lise & 98 & 33,8 \\
\hline & Üniversite & 6 & 2,1 \\
\hline \multirow{3}{*}{ Kidem } & $1-5$ & 217 & 75,3 \\
\hline & $6-10$ & 71 & 21,7 \\
\hline & $11+$ & 2 & 3 \\
\hline
\end{tabular}

Tablo 1 incelendiğinde araştırmaya katılan örneklem grubunun ağrılıklı olarak kadın; yaş sıklığının; 40 yaş ve üzeri; eğitim durumlarının lisans; branşlarının diğer, çalıştıkları kurumun kamu, kademelerinin lise ve kıdem yıllarının da ağırlıklı olarak 1-5 yıl olduğu ortaya konulmuştur.

\section{Veri Toplama Araçları}

Araştırmada Türkçeye uyarlanan orijinal ölçeğe ait bilgiler aşağıda verilmiştir:

\section{Problemli Akıllı Telefon Kullanımı ve Ön Psikometrik Özellikleri Ölçeği}

$\mathrm{Bu}$ çalışmada, bireylerin problemli akıllı telefon kullanımları ve ön psikometrik özelliklerinin belirlenmesi adına Merlo, Stone ve Bibbey (2013) tarafından geliştirilen ilgili ölçeğin Türkçeye uyarlama çalışması yapılmıştır. Ölçek 20 maddeden oluşup, ölçek maddelerinin cevaplandırılmasında "Kesinlikle Katılmıyorum-Katılmıyorum-Kararsızım-Katılıyorum-Kesinlikle Katıllyorum" şeklinde 5'li likert ölçeğinden yararlanılmıştır. Orijinal ölçek tek faktörlü bir yapıyı desteklemektedir.

Ölçeğin geçerlik ve güvenirlik çalışmaları, kamu ve özel eğitim kurumlarında çalışan 290 öğretmenden elde edilen verilerle gerçekleştirilmiştir. Elde edilen sonuçlara göre; iç tutarlılık katsayısı mükemmel olarak tespit edilip ( $\alpha=.94)$ maddeler arasında güçlü korelasyonlar $(r=.76, p<.00)$ saptanmıştır. Ölçek maddelerinin faktör yükleri .66 ile .93 arasında değişmektedir. Sonuç olarak ilgili 
ölçek Problemli Akıllı Telefon Kullanımını ve Ön Psikometrik Özelliklerini test eden güçlü bir ölçek olarak kabul edilebilmektedir.

Problemli Akıllı Telefon Kullanımı ve Ön Psikometrik Özellikleri Ölçeği’nin uyarlama çalışmasını yapmak için öncelikle ölçeği geliştiren kişi olan Lisa Merlo'dan izin alınmıştır. Ölçeğin İngilizce formu, İngilizce ve Türkçeye hâkim bir uzman aracılığıyla Türkçe'ye çevrilmiştir. Alınan uzman görüşlerinden sonra gerekli görülen düzenlemeler yapılmış ve pilot uygulama için deneme formu oluşturulmuştur. Pilot uygulamada, asıl uygulamaya eş değer 15 kişilik bir grup ile çalışılmıştır. Pilot uygulama sonucunda öğrenciler tarafından anlaşılmayan maddeler değiştirilmiş ve tekrar uzman görüşü alındıktan sonra ölçeğin asıl formu oluşturulmuştur. Oluşturulan Türkçe form, bir dil uzmanı akademisyene verilerek kontrolü sağlanmıştır. Alınan geri dönütlere göre ölçeğin Türkçe formu İngilizce formunu yakın olarak görülmüştür. Ardından ilgili maddelerin amaca hizmet edip etmediğini tespit etmek üzere 3 alan uzmanı, 1 psikolojik danışman ve 1 ölçme değerlendirme uzmanından görüşler alınmıştır.

Ölçeğin dilsel eşdeğerliliğini test etmek için, İngilizce yeterliliği olan öğretmenlere iki hafta arayla önce ölçeğin İngilizce formu daha sonra Türkçe formu uygulanmıştır. Son hali verilen ölçme aracı, Sakarya ili kamu ve özel eğitim kurum ve kuruluşlarında görev yapan farklı branşlardaki öğretmenlere 3 hafta içinde uygulanmıştır. Ölçeğin geçerliği adına yapı geçerliği (açımlayıcı ve doğrulayıcı faktör analizi) irdelenmiştir. Ölçeğin güvenirliği ise Cronbach alfa katsayısı ile saptanmıştır. Araştırmanın verileri SPSS 24.0 ve AMOS 24.0 programları ile analiz edilmiştir.

290 kişilik gruba yapılan ön uygulama sonucunda elde edilen ölçek maddeleri ile ortalama ve standart sapma değerleri Tablo 2'de verilmiştir.

Tablo 2

Problemli Akıllı Telefon Kullanımı ve Ön Psikometrik Özellikleri Ölçek Maddeleri Ortalama ve Standart Sapma Değerleri Pilot Uygulama Sonuçları

\begin{tabular}{|c|c|c|}
\hline Madde ve Faktörler & $\boldsymbol{X}$ & SD \\
\hline S22. Ak1llı telefonumu az kullandığım zaman kendimi daha az hoşnut hissediyorum & 3,40 & 1,38 \\
\hline $\begin{array}{l}\text { S23. Kendimi daha hoşnut hissetmem için akıllı telefonumu kullanmaya daha fazla vakit } \\
\text { ayırmalıyım }\end{array}$ & 3,04 & 1,73 \\
\hline S24. Ak1llı telefonumu kullanmayı bıraktığımda karamsar ve huzursuz oluyorum & 2,51 & 1,50 \\
\hline S25. Akıllı telefonumu kullanmayı bıraktığımda duygusal açıdan çok zorlanıyorum & 2,54 & 1,47 \\
\hline S26. Ak1llı telefonumu kullanmaya harcadığım zaman, diğer önemli işlerime engel oluyor & 3,04 & 1,44 \\
\hline $\begin{array}{l}\text { S27. Geçmişi düşündüğümde akıllı telefonumla geçirdiğim zamanın normal olmadığını } \\
\text { düşünüyorum }\end{array}$ & 3,55 & 1,42 \\
\hline S28. Akıllı telefonumla çok fazla zaman harcadığıma inanıyorum & 3,46 & 1,41 \\
\hline $\begin{array}{l}\text { S29. İnsanlar (ailem, arkadaşlarım) akıllı telefonumda çok fazla zaman harcadığımı } \\
\text { söylüyor. }\end{array}$ & 2,66 & 1,64 \\
\hline $\begin{array}{l}\text { S30. Akıllı telefonumu kullanmadığım zamanlarda, o an ya da bir sonraki sefer } \\
\text { kullanmayı düşünüyorum. }\end{array}$ & 3,14 & 1,62 \\
\hline S31. Çağrı ya da mesaj almadığım zamanlarda kaygılı hissediyorum & 3,18 & 1,55 \\
\hline $\begin{array}{l}\text { S32. Akıllı telefonumu kullanırken yanımda bulunan kişileri (ailem, arkadaşlarım) } \\
\text { görmezden geldiğimi fark ediyorum }\end{array}$ & 3,65 & 1,63 \\
\hline S33. İş ya da okulla ilgili çalışmalar yapmam gerektiğinde akıllı telefonumu kullanırım & 3,17 & 1,47 \\
\hline S34. Uyumam gerektiğini bildiğim hâlde akıllı telefonumu kullanmaya devam ediyorum & 3,39 & 1,76 \\
\hline $\begin{array}{l}\text { S35. Akıllı telefonumu kullanmayı bıraktığımda hayatım etkilendiğini zannedip onu tekrar } \\
\text { kullanmaya devam ediyorum }\end{array}$ & 3,45 & 1,84 \\
\hline S36. Akıllı telefonumu çok kullandığım için iş yeri ya da okulda sorun yaşıyorum & 2,62 & 1,62 \\
\hline $\begin{array}{l}\text { S37. Benim için önemli olan ve benimle zaman geçirmek isteyen insanlar yerine akılllı } \\
\text { telefonumla vakit geçiriyorum }\end{array}$ & 3,29 & 1,41 \\
\hline $\begin{array}{l}\text { S38. Akıllı telefon kullanmanın tehlikeli olduğunu bildiğim hâlde onu kullanmaya devam } \\
\text { ediyorum }\end{array}$ & 2,89 & 1,74 \\
\hline S39. Ak1llı telefonumu kullanırken neredeyse bir kazaya neden oluyordum & 3,39 & 1,48 \\
\hline S40. Akıllı telefonun ilişkilerimde sorunlara neden olduğunu düşünüyorum & 3,22 & 1,76 \\
\hline
\end{tabular}




\begin{tabular}{lcc}
\hline S41. Biri bana soru sorduğunda bile akıllı telefonumu kullanmaya devam ediyorum & 3,29 & 1,71 \\
\hline Genel Ortalama & $\mathbf{3 , 1 4}$ & $\mathbf{1 , 5 7}$ \\
\hline
\end{tabular}

20 madde için ortalamanın 3,55 ile 2,17 değerleri arasında Kesinlikle Katılmıyorum: değiştiği ortaya konulmuştur. Sonuçların yorumlanmasında kullanılan puan sınırları; 1,00-1,79; 1,80-2,59; 2,603,39; 3,40-4,19; 4,20-5,00 (Büyüköztürk, Kılıç, Akgün, Karadeniz ve Demirel, 2013) değerleri arasında kabul görülmüştür. Bu bağlamda ilgili anket için tüm maddelerin genel ortalaması 3,14 olduğundan öğretmenlerin problemli akıllı telefon kullanımına yönelik yanıtlarının genel olarak "Kararsızım” seçeneği üzerinde yoğunlaştığı anlaşılmaktadır.

\section{Bulgular}

\section{Geçerlik}

Problemli Akıllı Telefon Kullanımı ve Ön Psikometrik Özellikleri ölçeğinin görünüş ve kapsam geçerliği için 1 dil uzmanına, 3 alan uzmanına, 1 psikolojik danışmana ve 1 ölçme değerlendirme uzmanının görüşüne başvurulmuştur.

Yapı geçerliği için açımlayıcı faktör analizi (AFA) yapılmıştır. Açımlayıcı faktör analizi (AFA) sonuçlarına göre toplam varyansın \%54,76'sını açıklayan 20 maddeden oluşan 3 boyutlu bir ölçek elde edilmiştir. Elde edilen sonuçlara göre; özdeğeri 1'den büyük ölçek maddesi tespit edilmediğinden orijinal ölçekte herhangi bir madde çıkarılmamıştır. Açıklanan varyansın \%30 değerinin üzerinde olması, sosyal bilimlerde yapılan test geliştirme çalışmalarında yeterli olarak tanımlanmaktadır (Büyüköztürk, vd., 2013).

\section{Açımlayıcı Faktör Analizi}

Ölçekten elde edilen veriler normal dağıldığından faktör analizi yapılırken "principal component analysis" den yararlanılmıştır. Bu analiz toplam varyans üzerinden hesaplama yapar. Dolayısıyla faktörler üzerinde değişkenin kendisinde gözlenen özgül varyans ve veri setine ilişkin açıklanamayan kısım olarak tanımlanan hata varyansı da hesaba katılmış olur (Gorsuch, 1990).

Açımlayıcı faktör analizi için ilk adım olarak; örneklemin yeterliliğini test eden Kaiser-MeyerOlkin (KMO) testi ele alınmıştır. KMO değeri ise .91 olarak tespit edilmiştir. İlgili değerin .70'in üzerinde olması nedeni ile bu veriler üzerinden faktör analizi yapılabileceği saptanmıştır (Büyüköztürk, vd,. 2013; Hutcheson ve Sofroniou, 1999). Sonraki adım olarak Barlett Sphericity testine bakılarak $\left(\mathrm{x}^{2}=2759,244 \mathrm{p}=, 000\right)$ verilerin anlamlı farklılık gösterdiği ve faktör analizi yapmak için uygun olduğu tespit edilmiştir.

Açımlayıcı faktör analizinden elde edilen bulgular ölçeğin üç boyutlu bir yapısının doğruluğunu göstermektedir. İlgili boyutlar uzman görüşü alınarak "bağımlılık", "kaygl"ve "engeller" şeklinde araştırmacılar tarafından isimlendirilmiştir. 


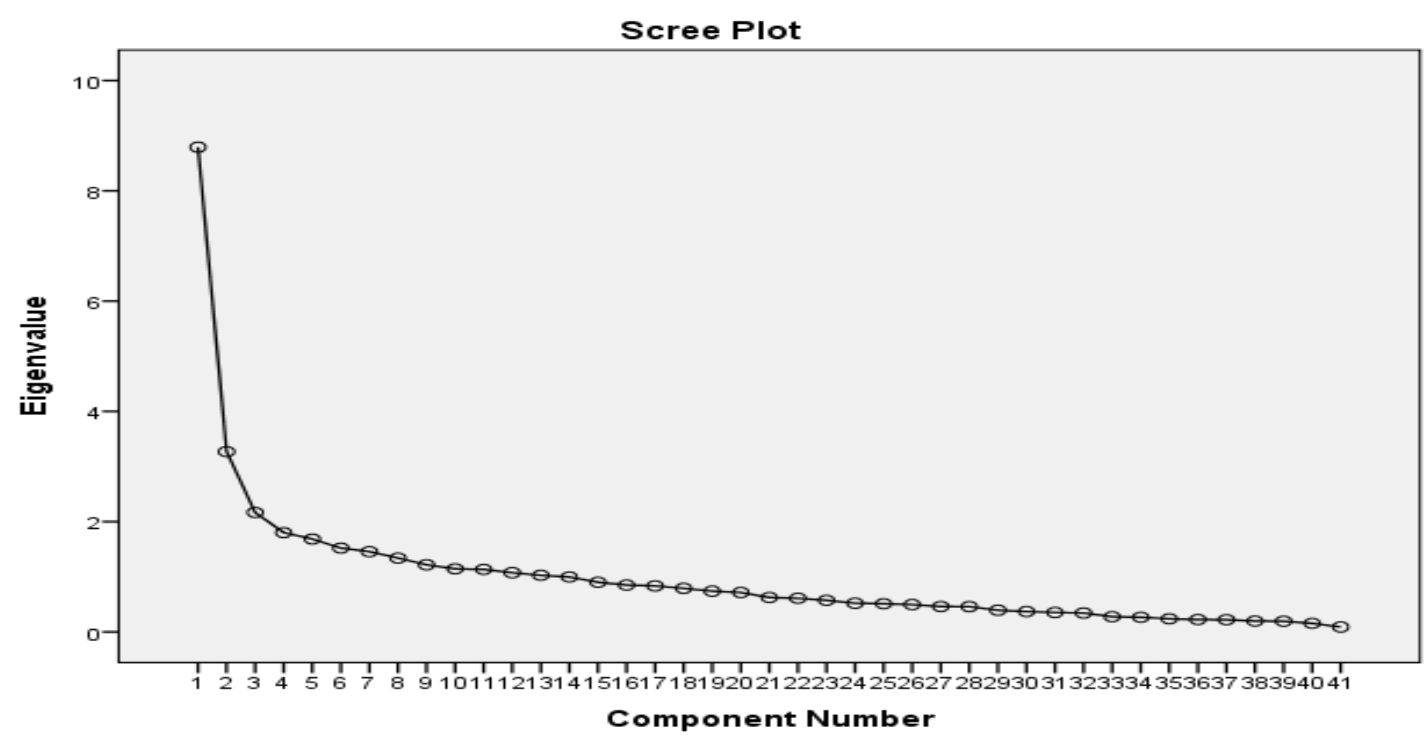

Grafik 1. Problemli Akıllı Telefon Kullanımı ve Ön Psikometrik Özellikleri Ölçeğinin Özdeğer-Faktör Sayıs1 Grafiği

Ölçek maddelerinin yer aldığı faktörlerdeki yük değerleri ile madde ortak faktör varyansı Tablo 3'te belirtilmiştir.

Tablo 3

Açımlayıcı Faktör Analizi Sonuçları

\begin{tabular}{|c|c|c|c|c|c|c|c|c|c|}
\hline & \multicolumn{3}{|c|}{ Başlangıç Özdeğerleri } & \multicolumn{3}{|c|}{ Yükler Karesinin Çıkarımı Toplamı } & \multicolumn{3}{|c|}{$\begin{array}{l}\text { Yükler Karesinin Döndürme } \\
\text { Toplamı }\end{array}$} \\
\hline & Toplam & $\begin{array}{c}\text { Varyans } \\
\%\end{array}$ & $\begin{array}{c}\text { Birikimli } \\
\%\end{array}$ & Toplam & $\begin{array}{c}\text { Varyans } \\
\%\end{array}$ & $\begin{array}{c}\text { Birikimli } \\
\% \\
\end{array}$ & Toplam & $\begin{array}{c}\text { Varyans } \\
\%\end{array}$ & $\begin{array}{c}\text { Birikimli } \\
\% \\
\end{array}$ \\
\hline 1 & 9.992 & 41.749 & 41.749 & 9.992 & 41.749 & 41.749 & 4.692 & 19.604 & 19.604 \\
\hline 2 & 1.608 & 6.719 & 48.468 & 1.608 & 6.719 & 48.468 & 4.222 & 17.639 & 37.242 \\
\hline 3 & 1.508 & 6.299 & 54.767 & 1.508 & 6.299 & 54.767 & 4.194 & 17.525 & 54.767 \\
\hline
\end{tabular}

Tablo 3 incelendiğinde, ölçeğin 3 faktörlü bir yapıdan oluştuğu görülmektedir. Ölçeğin 3 faktörlü yapısı, toplam varyansın \%54.76'sını açıklamaktadır. Bu sonuçlar ölçeğin, Problemli Akıllı Telefon Kullanımı ve Ön Psikometrik Özelliklerini iyi bir şekilde açıkladığını göstermektedir. Ölçekte toplam 20 ifade yer almıştır. "Bağımlılık" boyutunda (8) madde; "Kaygı" boyutunda (8) madde; "Engeller" boyutunda (4) madde yer almaktadır.

\section{Güvenirlik}

Çalışmanın güvenirliğini test etmek amacıyla ölçeğin 20 maddeden oluşan 3 faktörlü yapısının Cronbach Alpha ile saptanan iç tutarlık katsayısı .91 olarak belirlenmiştir. Ölçeğin alt boyutlarına yönelik yapılan istatistiksel analizler sonunda Cronbach Alpha ile hesaplanan iç tutarlık katsayıları bağımlılık boyutuna yönelik .83; kaygı boyutuna yönelik .86 ve engeller boyutuna yönelik .80 şeklinde tespit edilmiştir. Araştırmacılara göre güvenirlik katsayısı 1'e yaklaştı̆̆ında güvenirlik artmaktadır (Huang, Ryan, Zaber ve Palmer, 2014; Sekaran, 2003). Alanyazın incelendiğinde, Fraenkel ve Wallen (2006) güvenirlik katsayısının .60'tan düşük olması ölçeğin oldukça zayıf olduğunu, .60 ile .70 arasında olması kabul edilebilir sınırlar içerisinde olduğunu ve .80 üzerinde olmasının ise iyi olduğunu göstermektedir. Bu bağlamda ölçeğin ilgili boyutlarının her birinin güvenirlik katsayılarının iyi olduğu yorumu yapılabilmektedir. 


\section{Doğrulayıcı Faktör Analizi}

$\mathrm{Bu}$ çalışmada Açımlayıcı faktör analizinde kullanılan aynı veriler üzerinden Doğrulayıcı faktör analizine gidilmiştir. Alan yazın incelendiğinde Schmitt (2011) yaptığı çalışmada aynı veriye önce AFA uygulayarak elde edilen yapıyı doğrulamak için DFA uygulamıştır. Önce açımlayıcı faktör analizi uygulanıp, açımlayıcı faktör analizi ile keşfedilen modelin doğrulayıcı faktör analizi ile test edilmesi ve kuramsal sağlamlığı yakalanmıştır.

\section{Bă̆ımlılık Faktörü DFA}

Kavramsal çerçevede değerlendirilen ölçeğin Bağımlılık Faktörüne ait doğrulayıcı faktör analiz sonuçları şekil 1'de görülmektedir.

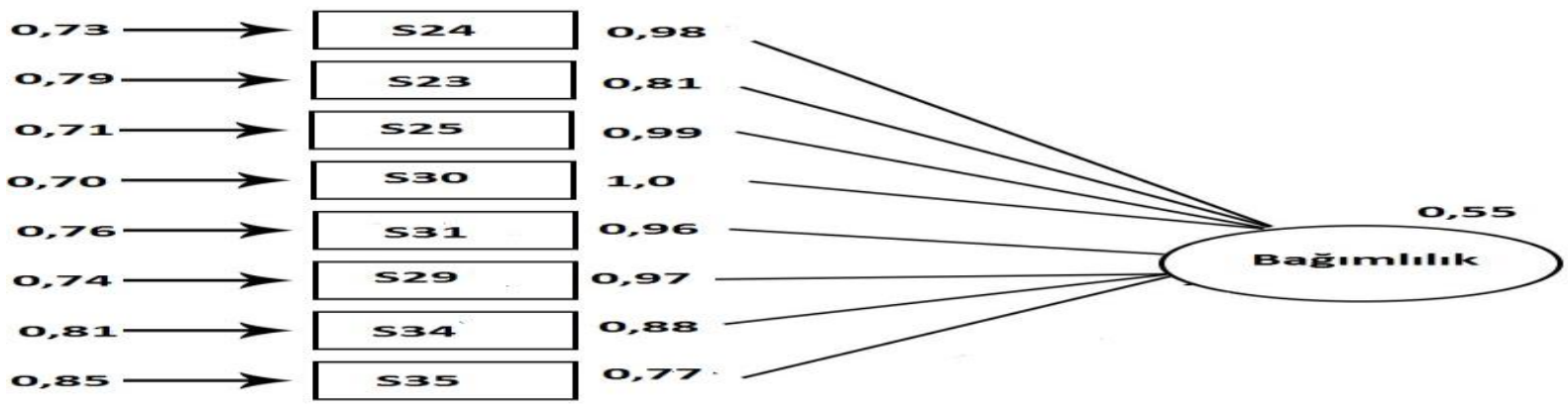

Şekil 1. Bağımlılık Faktörü İçin DFA

Şekil 2'deki DFA'da, Bağımlılık faktöründen gözlenen değişkenlere doğru yönlendirilmiş oklar üzerindeki değerler faktörün açıklanmasında yararlanılan her bir gözlenen değişkene ait standart regresyon katsayılarını (doğrulayıcı faktör analizi yükleri) göstermektedir. Şekil 2'de yer alan gözlenen değişkenlere ait hata değerleri $\left(1-R^{2}\right.$ sonuçları) ise hata değerlerinden her bir gözlenen değişkene doğru yönlendirilmiş oklar üzerinde görülmektedir.

Tablo 4

Băgımlık Faktörü Uyum İndeksleri

\begin{tabular}{ccccccc}
\hline & \multicolumn{7}{c}{ Uyum İndeksleri } \\
\cline { 2 - 6 } Özellikler & $\chi^{2} / \mathrm{df}$ & GFI & AGFI & TLI & CFI & RMSEA \\
& $75,2 / 20$ &, 940 &, 891 &, 914 &, 0939 &, 0078 \\
\hline
\end{tabular}

Bağımlılık faktöre ait nihai uyum indeksleri, Tablo 4'te görüldüğü gibi istenilen sınırlarda olduğu gözlenmiştir. Modele ilişkin hesaplanan $\chi^{2} / \mathrm{df}$ oranının 3 'ten küçük olması mükemmel uyumun, 5 'ten küçük olması kabul edilebilir uyumun göstergelerindendir (Kline, 2005; Sümer, 2000). Ayrıca GFI ve AGFI değerlerinin 0.90'dan yüksek olması, RMSEA değerinin ise 0.08 den düşük çıkmas1, model veri uyumunu göstermektedir (Marsh ve Hocevar, 1988). Bununla birlikte, GFI'nin 0.85 'ten, AGFI nin 0.80 'den büyük çıkması, RMR ve RMSEA değerlerinin 0.10'dan düşük çıkması, model veri uyumu için kabul edilebilir alt sınırlar olarak kabul edilmektedir (Anderson ve Gerbing, 1984; Cole, 1987). Araştırmaya yönelik direnç ölçeğinin geçerlik çalışmaları olarak gerçekleştirilen doğrulayıcı faktör analizi çalışmaları sonucuna göre, önerilen modele ilişkin uyum indekslerinden GFI'nin .94, AGFI'nın .89, CFI'nin .93, modelin mükemmel uyum gösterdiğini kanıtıdır.

\section{Kaygı Faktörü DFA}

Kavramsal çerçevede değerlendirilen ölçeğin Kaygı Faktörüne ait doğrulayıcı faktör analiz sonuçları şekil 2'de görülmektedir. 


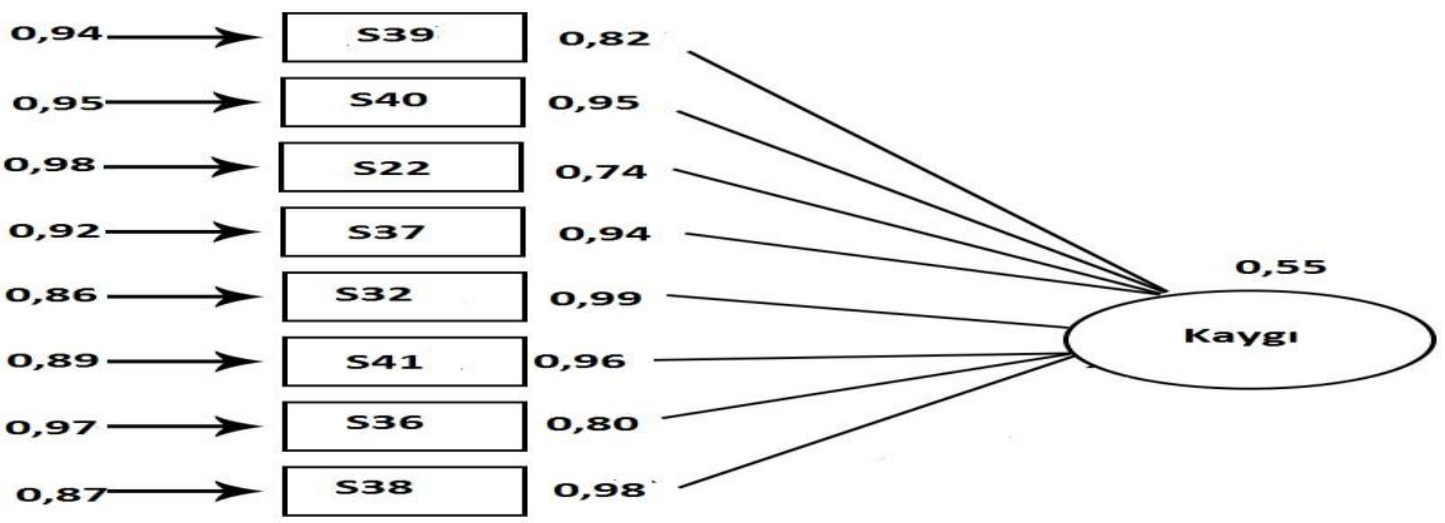

Şekil 2. Kayg1 Faktörü İçin DFA

Şekil 2'deki DFA'da, Kaygı faktöründen gözlenen değişkenlere doğru yönlendirilmiş oklar üzerindeki değerler faktörün açıklanmasında yararlanılan her bir gözlenen değişkene ait standart regresyon katsayılarını (doğrulayıcı faktör analizi yükleri) göstermektedir. Şekil 3'de yer alan gözlenen değişkenlere ait hata değerleri $\left(1-\mathrm{R}^{2}\right.$ sonuçları) ise hata değerlerinden her bir gözlenen değişkene doğru yönlendirilmiş oklar üzerinde görülmektedir.

Tablo 5

Kaygı Faktörü Uyum İndeksleri

Uyum İndeksleri

Özellikler

\begin{tabular}{cccccc}
\hline$\chi^{2} / \mathrm{df}$ & GFI & AGFI & TLI & CFI & RMSEA \\
\hline $50,6 / 20$ &, 956 &, 921 &, 947 & 1,00, & 0,073 \\
\hline
\end{tabular}

Kayg1 faktöre ait nihai uyum indeksleri, Tablo 5'te görüldüğü gibi istenilen sinırlarda olduğu gözlenmiştir. GFI ve AGFI değerlerinin 0.90'dan yüksek olması, RMSEA değerinin ise 0.08 den düşük çıkması, model veri uyumunu göstermektedir (Marsh ve Hocevar, 1988).

\section{Engeller Faktörü DFA}

Kavramsal çerçevede değerlendirilen ölçeğin Engeller Faktörüne ait doğrulayıcı faktör analiz sonuçları şekil 4'te görülmektedir.
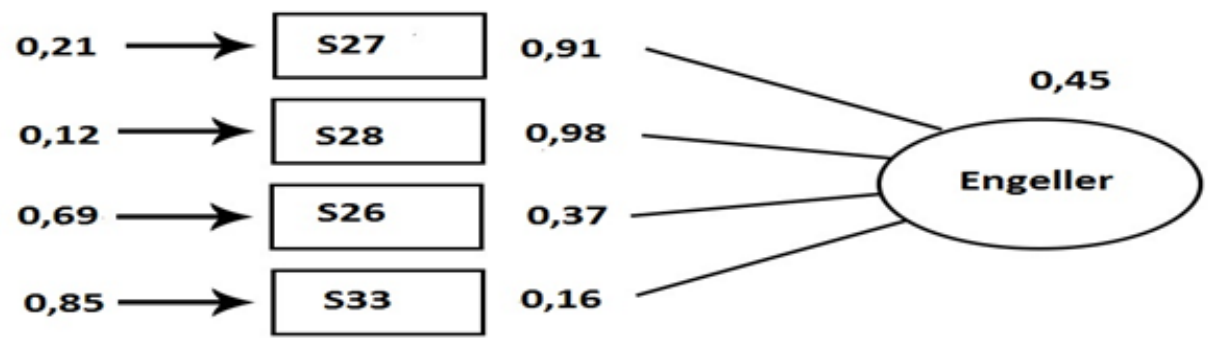

Şekil 3. Engeller Faktörü İçin DFA

Şekil 3’teki DFA'da, Bağımlılık faktöründen gözlenen değişkenlere doğru yönlendirilmiş oklar üzerindeki değerler faktörün açıklanmasında yararlanılan her bir gözlenen değişkene ait standart regresyon katsayılarını (doğrulayıcı faktör analizi yükleri) göstermektedir. Şekil 4'de yer alan 
gözlenen değişkenlere ait hata değerleri $\left(1-\mathrm{R}^{2}\right.$ sonuçları) ise hata değerlerinden her bir gözlenen değişkene doğru yönlendirilmiş oklar üzerinde görülmektedir.

Tablo 6

Engeller Faktörü Uyum Indeksleri

Uyum İndeksleri

Özellikler

\begin{tabular}{cccccc}
\hline$\chi^{2} / \mathrm{df}$ & GFI & AGFI & TLI & CFI & RMSEA \\
\hline $2,2 / 0,20$ &, 995 &, 975 &, 998 &, 999 &, 002 \\
\hline
\end{tabular}

Engeller faktöre ait nihai uyum indeksleri, Tablo 6'de görüldügü gibi istenilen sinırlarda olduğu gözlenmiştir.

Doğrulayıcı Faktör Analizi tanım olarak; daha önceden ortaya konulmuş bir yapının doğruluğunu test etmek amaciyla kullanılmaktadır (Bayram, 2010). Hooper, Caughlan ve Muller'e (2008) göre GFI, CFI, NFI, RFI, IFI ve AGFI indeksleri adına 0.90 kabul edilebilir uyum değeri, 0.95 ise mükemmel uyum değeri olarak kabul görmektedir. Bu bağlamda ilgili uyum indekslerinin mükemmel uyum değerlerini tespit ettiği saptanmıştır.

\section{Sonuç, Tartışma ve Öneriler}

Ölçeğin yapı geçerliği için açımlayıcı faktör analizi (AFA) yapılmıştır. Açımlayıcı faktör analizi (AFA) sonuçlarına göre toplam varyansın \%54.76'sını açıklayan 20 maddeden oluşan 3 boyutlu bir ölçek elde edilmiştir. Elde edilen sonuçlara göre; özdeğeri 1'den büyük ölçek maddesi tespit edilmediğinden orijinal ölçekte herhangi bir madde çıkarılmamıştır. Açıklanan varyans oranının \%30'un üzerinde olması, sosyal bilimlerde kullanılan test geliştirme çalışmalarında yeterli olarak kabul edilmektedir (Büyüköztürk, 2013).

Araştırmada örneklemin yeterliliğini test eden KMO değeri .91 olarak tespit edilmiştir. (Büyüköztürk, 2004; Hutcheson ve Sofroniou, 1999). Barlett Sphericity testi sonucuna göre $\left(\mathrm{x}^{2}=\right.$ $2759,244 \mathrm{p}=, 000)$ elde edilen verilerin anlamlı farklılık gösterdiği ve faktör analizi yapmaya uygun olduğu saptanmıştır. Sonuç olarak KMO ve Barlett testi, verilerin faktör analizi için uygun olduğunu göstermektedir. AFA' dan elde edilen sonuçlar ölçeğin üç boyutlu bir yapısını doğrulamaktadır. İlgili boyutlar; "bağımlılık", "kaygı" ve "engeller" boyutları olarak adlandırılmıştır. İlgili konuya yönelik geliştirilen ölçekler incelendiğinde; Yıldırım vd., (2016) çalışmalarında "Türkçe Nomofobi Ölçeğini" ortaya koymuşlardır. 5'li likert tipinde hazırlanan ölçek toplamda 20 maddeden oluşup, 4 boyutludur. $\mathrm{Bu}$ boyutlar, "bilgiye erişememe, rahatlıktan feragat etme, iletişim kuramama ve çevrimiçi bağlantıyı kaybetme" olarak belirlenmiştir.

Araştırmanın güvenirliğini belirlemek üzere ölçeğin 20 maddeden oluşan 3 faktörlü yapısının Cronbach Alpha ile belirlenen iç tutarlık katsayısı .91 olarak bulunmuştur. Alt boyutlarına ilişkin yapılan analizler sonucunda Cronbach Alpha ile hesaplanan iç tutarlık katsayıları bağımlılık boyutu için .83; kaygı boyutu için .86 ve engeller boyutu için .80 şeklindedir. Birçok araştırmacıya göre güvenirlik kat sayısı 1'e yaklaştığında güvenirlik artmaktadır (Huang, Ryan, Zaber ve Palmer, 2014; Sekaran, 2003).

Asıl uygulamaya yönelik 290 kişilik örneklem grubundan elde edilen verilerde, 20 madde için ortalamanın 3,55 ile 2,17 değerleri arasında değiştiği ortaya konulmuştur. Sonuçların yorumlanmasinda kullanılan puan sinırlar1; Kesinlikle Katılmıyorum: 1,00-1,79; Kat1lmıyorum: 1,802,59; Kararsızım: 2,60-3,39; Katılıyorum: 3,40-4,19; Kesinlikle Katılıyorum: 4,20-5,00 (Büyüköztürk, vd. 2013) değerleri arasında kabul görülmüsstür. Bu bağlamda ilgili anket için tüm maddelerin genel ortalaması 3,14 olduğundan öğretmenlerin problemli akıllı telefon kullanımına yönelik yanıtlarının genel olarak "Kararsızım" seçeneği üzerinde yoğunlaştığı anlaşılmaktadır. 20 madde içerisinde en yüksek ortalama maddesinin "Geçmişi düşündüğümde ak1llı telefonumla geçirdiğim zamanın normal 
olmadığını düşünüyorum" olduğu tespit edilmiştir. Bu tespit araştırmaya katılan pilot grubun nomofobik olduğu durumunu desteklemektedir.

Alanyazın incelendiğinde araştırma sonucuyla benzerlik gösteren çalışmalar tarandığında; Yıldırım, Sumuer ve Adnan (2015), Türkiye'de genç erişkinlerde nomofobinin (cep telefonu ile iletişim kurmama korkusu) yaygınlığını araştırdıkları çalışmalarında, geliştirdikleri Nomofobi ölçeğini 537 üniversite öğrencilerine uygulamışlardır. Sonuç olarak araştırmanın sonunda, genç yetişkinlerin $\% 42,6$ 'sının nomofobik olduğu yaşadıkları en büyük korkunun ise iletişim ve bilgiye erişimin kesilmesi olduğu ortaya konulmuştur. Akıllı ve Gezgin (2016) ise yaptıkları çalışmada üniversite öğrencilerinin nomofobi düzeyleri ile farklı davranış örüntülerinin arasındaki ilişkileri incelemişlerdir. $\mathrm{Bu}$ bağlamda 683 üniversite öğrencisi ile çalışmışlar, sonuç olarak nomofobik bireylerin, gün içerisinde sıklıkla telefonlarını kontrol ettiklerini, yanlarında şarj aleti taşıdıklarını, gece telefonlarını açık tuttukları ve uyanır uyanmaz telefonlarını kontrol ettikleri tespit edilmiştir.

Nomofobi hakkında öğrencilere farkındalık kazandırmak ve olumsuz yönlerinden korumak amaciyla üniversitelerde öğrencilere bilgilendirici seminerler, konferanslar düzenlenebilir. Nomofobi düzeyi yüksek olan öğrenciler tespit edilerek bu öğrenciler sportif ve sosyal faaliyetlere yönlendirilebilir. Böylece öğrencilerin akıllı telefonlarıyla fazla vakit geçirmesinin önüne geçilebilir.

\section{Kaynaklar}

Adnan, M. ve Gezgin D. M. (2016). Modern çağın yeni fobisi: Üniversite öğrencileri arasında nomofobi prevalans1. Ankara Üniversitesi Eğitim Bilimleri Fakültesi Dergisi, 49(1), 141-158.

Akıllı, G. K. and Gezgin, M. D. (2016). Examination of relationship between university students' nomophobia levels and behavior patterns. Mehmet Akif Ersoy Üniversitesi Ë̆itim Fakültesi Dergisi. 40(1), 51-69.

Anshari, M., Alas, Y., Hardaker, G., Jaidin, J. H., Smith, M. and Ahad, A. D. (2016). Smartphone habit and behavior in Brunei: Personalization, gender, and generation gap. Computers in Human Behavior, 64, 719-727.

Anderson, J. C. and Gerbing, D. W. (1984). The effect of sampling error on convergence, improper solutions, and goodness-offit indices for maximum likelihood confirmatory factor analysis. Psychometrika, 49, 155-173.

Büyüköztürk, Ş., Kılıç, Ç. E., Akgün, Ö. E., Karadeniz, Ş. ve Demirel, F. (2013). Bilimsel araştırma yöntemleri (2.Basım). Ankara: Pegem Akademi.

Cole, D. A. (1987), Utility of Confirmatory Factor Analysis in Test Validation Research. Journal of Consulting and Clinical Psychology, 55, 1019-1031.

Dağl1, E. S., Hamutoğlu, N. B. ve Gezgin, D. M. (2017). Okul öncesi ögretmenlerinin nomofobi düzeyleri ile akall telefon ve sosyal ăg servisleri kullanma davranışları arasındaki ilişkinin incelenmesi. 11.Uluslararası BÖTE Sempozyumu. İnönü Üniversitesi, Malatya.

Dixit, S., Shukla, H., Bhagwat, A., Bindal, A., Goyal, A., Zaidi, A. and Shrivastava, A. (2010). A Study to evaluate mobile phone dependence among students of a medical college and Associated Hospital of Central India. Indian Journal of Community Medicine, 35(2), 339-341.

Fraenkel, J. R. and Wallen, N. E. (2006). How to design and evaluate research in education (6th ed.). New York: NY McGraw-Hill.

Gezgin, D.M. and Çakır, Ö. (2016). Analysis of nomopfobic behaviors of adolescents regarding various factors. Journal of Human Science, 13(2), 2504-2519. 
Gorsuch, R. L. (1990) Common factor-analysis versus component analysis: some well and little known facts. Multivariate Behavioral Research, 25, 33-39.

Hutcheson, G. ve Sofroniou, N. (1999) The Multivariate Social Scientist. Sage: London.

Huang, J. L., Ryan, A. M., Zabel, K. L. and Palmer, A. (2014). Personality and adaptive performance at work: A metaanalytic investigation. Journal of Applied Psychology, 99(1), 162-179.

Kağızmanlı, T., B., Tatar, E. ve Zengin, Y. (2013). Öğretmen adaylarının matematik öğretiminde teknoloji kullanımına ilişkin algılarının incelenmesi. Ahi Evran Üniversitesi Kırşehir Eğitim Fakültesi Dergisi, 14(2), 349-370.

Kaplan-Akıllı, G. ve Gezgin, D. M. (2016). Üniversite öğrencilerinin nomofobi düzeyleri ile farklı davranış örüntülerinin arasındaki ilişkilerin incelenmesi. Mehmet Akif Ersoy Üniversitesi Ĕ̌itim Fakültesi Dergisi, 40, 51-69.

Kline, R. B. (2005). Principles and practice of structural equation modeling. NY: The Guillford Press.

Kwon, M., Kim, D. J., Cho, H. and Yang, S. (2013). The smartphone addiction: Development and validation of a short version for Adolescents (SAS-SV). PLOS ONE, 8(12), e83558.

Marsh, H. W. and Hocevar, D. (1988). A new, more powerful approach to multitrait-multimethod analyses: Application of second-order confirmatory factor analysis. Journal of Applied Psychology, 73(1), 107-117.

Merlo, L. J., Stone, A. and Bibbey, A. (2013). Measuring problematic mobile phone use: Development and preliminary psychometric properties of the PUMP Scale. Hindawi Publishing Corporation Journal of Addiction, 2013, 1-7.

Monette, D. R., Sullivan, T. J. and De Jong, C. R. (2005) Applied social research: A tool for the human services. Thomson Brooks/Cole: London.

Özbay, Ö. ve Sarıca, R. (2019). Ters yüz sınıfa yönelik gerçekleștirilen çalışmaların eğilimleri: Bir sistematik alanyazın taraması. Ahi Evran Üniversitesi Sosyal Bilimler Enstitüsü Dergisi, 5(2), 332-348.

Pavithra, M. B. and Madhukumar, S. (2015). A study on nomophobia-mobile phone dependence, among students of a Medical College in Bangalore. National Journal of Community Medicine, 6(3), 340- 344.

Sarı, İ. ve Kartal, F. (2018). Sosyal Bilgiler öğretmen adaylarının teknoloji kullanımına yönelik tutumlarının bireysel yenilikçilik düzeyleri ve bazı değişkenler açısından incelenmesi. Ahi Evran Üniversitesi Kırşsehir Ë̆itim Fakültesi Dergisi, 19(2), 1673-1689. DOI:10.29299/kefad.2018.19.02.017

Schmitt, R. S. (2011). Current methodological considerations in exploratory and confirmatory factor analysis. Journal of Psychoeducational Assessment, 29(4), 304-321. doi:10.1177/0734282911406653.

Sekaran, U. (2003). Research Methods for Business A Skill-Building Approach. 4th Edition, John Wiley \& Sons: New York. 
Sharma, N., Sharma, P., Sharma, N. and Wavare, R. R. (2015). Rising concern of nomophobia amongst 1ndian medical students. http://imsear.li.mahidol.ac.th/handle/123456789/165807 adresinden 09.09.2019 tarihinde erişilmiştir.

Sümer, N. (2000). Yapısal esitlik modelleri: Temel kavramlar ve örnek uygulamalar. Türk Psikoloji Yazıları, 3(6), 49-74.

Yildirim, C. and Correia, A. P. (2015). Exploring the dimensions of nomophobia: Development andvalidation of a self-reported questionnaire. Computers in Human Behavior, 49, 130-137.

Yıldırım, Ç., Sumuer, E. and Adnan, M. (2016). A growing fear: Prevalence of nomophobia among Turkish college students. https://journals.sagepub.com/doi/10.1177/0266666915599025 adresinden 19 Eylül 2019 tarihinde erişilmiştir.

Yüksel, M. and Durmaz, A. (2016). The effect of perceived socially motivated gamification on purchase intention: Does it really work?. Ahi Evran Üniversitesi Sosyal Bilimler Enstitüsü Dergisi, 2(3), 15-25.

Tavolacci, M. P., Meyrignac, G., Richard, L., Dechelotte, P. and Ladner, J. (2015). Problematic use of mobile phone and nomophobia among French college students. The European Journal of Public Health, 25(suppl 3), ckv172-088.

Tavşancıl E., (2006). Tutumların ölçülmesi ve SPSS ile veri analizi. Ankara: Nobel Yayın Dağıtım.

Thomée, S., Harenstam A. and Hagberg, M. (2011). Mobile phone use and stress, sleep disturbances and symptoms of depression among young adults: A prospective cohort study. BMC Public Health, 66, 1-11. 


\section{Extended Abstract}

\section{Introduction}

Nowadays, the information and communication technologies that are developing and constantly changing have prepared the ground for the entry of some dependencies into our lives. One of these dependencies is nomophobia. Rapid developments and changes in information and communication technologies have enabled technology to be placed in the center of individuals' lives. In this context, individuals started to manage all their jobs in areas such as workplace, school, bank, regardless of time and place with just one button. Smart phones are one of the most important tools that bring such facilities to human life. In this sense, mobile phones have become the indispensable of the users of all ages with the features of smart phones by bringing different designs along with the developing technology. In line with these rates, this indulgence towards smartphones and the fear of not being able to access the opportunities offered by smartphones have led to psychological disorders in individuals. A researcher at the University of Connecticut; David Greenfield described this addiction with the word Nomophobia (Nomophobia), which consists of the combination of the words NO MOBILE PHONE in English. The possibilities offered by the new technologies can be summarized within the scope of personal computers, tablets and smart phones. With the revolutionary impact that the Internet provides with the use of these devices, obsession and addiction-like behaviors have been observed for a long time. Nomophobia, which is accepted as the disease of today, is defined as fear of being deprived of mobile phone. This disease, which is a modern age syndrome, has started to increase with the popularity of social media as well as smart phones. Considering the use of smart phones in our country, it is important to determine the behavioral responses of individuals towards problematic smart phones. In particular, it is clear that this concern affects individuals' focus on daily work.

\section{Method}

In this study, adaptation of the related scale developed by Merlo, Stone and Bibbey (2013) to Turkish in order to determine problematic smartphone usage and preliminary psychometric properties of individuals was conducted. In order to make the adaptation of the Measuring Problematic Mobile Phone Use: Development and Preliminary Psychometric Properties of the PUMP Scale, permission was obtained from Lisa Merlo, who developed the scale. The English form of the scale was translated into Turkish by a linguist who is fluent in English and Turkish. The Turkish form was submitted to a language expert academician to ensure control. According to the feedback, the Turkish form of the scale was found to be close to the English form. Afterwards, opinions were taken from 3 field experts, 1 psychological counselor and 1 measurement and evaluation expert to determine whether the relevant items served the purpose. As a result, the scale was finalized according to the opinions and suggestions received from the experts. After the expert opinions, necessary arrangements were made and a trial form was created for the pilot application. In the pilot application, a group of 15 people who were equivalent to the main application was studied. The actual application of the scale was carried out through a sample group of 290 people.

\section{Findings and Result}

As a result of the pilot application, items which were not understood by the teachers were changed and the original form of the scale was formed after the expert opinion was taken again. In order to test the linguistic equivalence of the scale, firstly the English form of the scale and then the Turkish form were applied to the teachers with English proficiency at two-week intervals. The assessment tool, which was prepared after the linguistic equivalence study, was applied to teachers from different branches working in public and private educational institutions and organizations of Sakarya within 3 weeks. For the validity of the scale, construct validity (exploratory and confirmatory factor analysis) was examined. The reliability study was examined by Cronbach's alpha coefficient and test-retest method. In addition, the differences between the item mean scores of the upper and lower $27 \%$ and $27 \%$ groups according to the total scores of test were tested using unrelated t-test. The data 
of the study were analyzed with SPSS 24.0 and AMOS 24.0 programs. Exploratory Factor Analysis (AFA) was used to serve construct validity. In order to determine the reliability of the study, Cronbach Alpha internal consistency coefficient of 3-factor structure of the scale consisting of 20 items was found to be .91 . As a result of the analysis of the sub-dimensions, the internal consistency coefficients calculated with Cronbach Alpha were found to be $.83 ; .86$ for anxiety dimension and .80 for obstacles dimension. Accordingly, it can be said that the reliability coefficients of each of the related dimensions of the scale are good. The final fit indexes were found to be within the desired limits in the context of 3-dimensional confirmatory factor analysis. As a result, when first and second level CFA compliance values of the scale are examined, it is seen that 3-factor structure of the scale, which consists of 20 items, generally shows good fit values, these values are acceptable and confirmed as a model.

\section{Discussion and Recommendations}

Among the 20 items, the highest average item was "I think that the time I spent with my smartphone is not normal when I think about the past". This finding supports the fact that the pilot group was nomophobic. Yildırım, Sumudu and Adnan (2015), in Turkey nomofobia of young adults (to communicate with mobile phones and fear) in their study investigated the prevalence, nomophobra scale they developed were applied to 537 university students. As a result, $42.6 \%$ of the young adults were nomophobic and the biggest fear they experienced was the deficiency of communication and access to information. Ak1llı and Gezgin (2016), in their study, examined the relationship between university students' nomophobia levels and different behavior patterns. In this context, they worked with 683 university students. As a result, it was found that nomophobic individuals frequently check their phones during the day, carry a charger, do not turn off their phones at night, spend time with their phones in bed before going to bed and check their phones as soon as they wake up. 